\title{
Presynaptic NMDA Receptor Mechanisms for Enhancing Spontaneous Neurotransmitter Release
}

\author{
Portia A. Kunz, ${ }^{1,2}$ Adam C. Roberts, ${ }^{1,2}$ and Benjamin D. Philpot ${ }^{1,2,3,4}$ \\ ${ }^{1}$ Department of Cell Biology and Physiology, ${ }^{2}$ Carolina Institute for Developmental Disabilities, ${ }^{3}$ Neuroscience Center, and ${ }^{4}$ Curriculum in Neurobiology, \\ University of North Carolina, Chapel Hill, North Carolina, 27599-7545
}

\begin{abstract}
NMDA receptors (NMDARs) are required for experience-driven plasticity during formative periods of brain development and are critical for neurotransmission throughout postnatal life. Most NMDAR functions have been ascribed to postsynaptic sites of action, but there is now an appreciation that presynaptic NMDARs (preNMDARs) can modulate neurotransmitter release in many brain regions, including the neocortex. Despite these advances, the cellular mechanisms by which preNMDARs can affect neurotransmitter release are largely unknown. Here we interrogated preNMDAR functions pharmacologically to determine how these receptors promote spontaneous neurotransmitter release in mouse primary visual cortex. Our results provide three new insights into the mechanisms by which preNMDARs can function. First, preNMDARs can enhance spontaneous neurotransmitter release tonically with minimal extracellular $\mathrm{Ca}^{2+}$ or with major sources of intracellular $\mathrm{Ca}^{2+}$ blocked. Second, lowering extracellular $\mathrm{Na}^{+}$levels reduces the contribution of preNMDARs to spontaneous transmitter release significantly. Third, preNMDAR enhance transmitter release in part through protein kinase $C$ signaling. These data demonstrate that preNMDARs can act through novel pathways to promote neurotransmitter release in the absence of action potentials.
\end{abstract}

\section{Introduction}

NMDA receptors (NMDARs) are critical for a wide range of neural functions, including memory formation, injury responses, and proper wiring of the developing nervous system (Cull-Candy et al., 2001; Pérez-Otaño and Ehlers, 2004; Lau and Zukin, 2007). Not surprisingly, NMDAR dysfunction has been implicated in a number of neurological disorders, including schizophrenia, Alzheimer's disease, epilepsy, ethanol toxicity, pain, depression, and certain neurodevelopmental disorders (Rice and DeLorenzo, 1998; Cull-Candy et al., 2001; Sze et al., 2001; Mueller and Meador-Woodruff, 2004; Coyle, 2006; Fan and Raymond, 2007; Autry et al., 2011). As a consequence, NMDARs are targets for many therapeutic drugs (Kemp and McKernan, 2002; Lipton, 2004; Autry et al., 2011; Filali et al., 2011).

Although most researchers have assumed a postsynaptic role for NMDARs, there is now compelling evidence that NMDARs can be localized presynaptically, where they are well positioned to regulate neurotransmitter release (Hestrin et al., 1990; Aoki et al., 1994; Charton et al., 1999; Corlew et al., 2007; Corlew et al., 2008; Larsen et al., 2011). Indeed, NMDARs can regulate spontaneous

\footnotetext{
Received May 23, 2012; revised March 22, 2013; accepted March 27, 2013.

Author contributions: P.A.K., A.C.R., and B.D.P. designed research; P.A.K. and A.C.R. performed research; P.A.K. and A.C.R. analyzed data; P.A.K., A.C.R., and B.D.P. wrote the paper.

This work was supported by the National Institute of Child Health and Human Development (Grant T32-HD40127 to P.A.M. and A.C.R.), the National Science Foundation (Grant 0822969 to B.D.P.), and the National Eye InstituteNational Institutes of Health (Grant R01EY018323 to B.D.P.). We thank members of the Philpot and Manis Laboratories for their helpful discussions and Rylan Larsen for his insightful comments on the manuscript.

The authors declare no competing financial interests.

Correspondence should be addressed to Dr. Benjamin D. Philpot, University of North Carolina, 115 Mason Farm Road, Chapel Hill, NC 27599-7545. E-mail: bphilpot@med.unc.edu.

DOI:10.1523/JNEUROSCI.2482-12.2013

Copyright $\odot 2013$ the authors $\quad 0270-6474 / 13 / 337762-08 \$ 15.00 / 0$
}

and evoked neurotransmitter release in the cortex and hippocampus in a developmental and region-specific manner (Berretta and Jones, 1996; Mameli et al., 2005; Corlew et al., 2007; Brasier and Feldman, 2008; McGuinness et al., 2010; Larsen et al., 2011). Presynaptic NMDARs (preNMDARs) are also critical for the induction of spike timing-dependent long-term depression (Sjöström et al., 2003; Bender et al., 2006; Corlew et al., 2007; Larsen et al., 2011), a candidate plasticity mechanism for refining cortical circuits and receptive field maps (Yao and Dan, 2005). The precise anatomical localization of preNMDARs has been debated (Christie and Jahr, 2008; Corlew et al., 2008; Christie and Jahr, 2009), but recent studies have shown that axonal NMDARs, rather than dendritic or somatic NMDARs on the presynaptic neuron, can increase the probability of evoked neurotransmitter release in the hippocampus (McGuinness et al., 2010; Rossi et al., 2012) and are required for timing-dependent long-term depression in the neocortex (Sjöström et al., 2003; Rodríguez-Moreno et al., 2010; Larsen et al., 2011). In addition to an increased understanding of the anatomical localization of preNMDARs, the molecular composition of preNMDARs is beginning to be elucidated. There is general agreement that cortical preNMDARs contain the GluN2B subunit (Bender et al., 2006; Brasier and Feldman, 2008; Larsen et al., 2011). At least in the developing visual cortex, preNMDARs require the GluN3A subunit to promote spontaneous, action-potential-independent transmitter release (Larsen et al., 2011).

However, despite advances in understanding the roles and molecular composition of preNMDARs, the cellular processes of preNMDAR-mediated release are poorly understood. Here we used a common assay for preNMDAR functions to probe pharmacologically the mechanisms by which these receptors promote 
spontaneous neurotransmitter release. Surprisingly, we found that preNMDARs can function in the virtual absence of extracellular $\mathrm{Ca}^{2+}$ in a protein kinase $\mathrm{C}$ (PKC)-dependent manner. Furthermore, in normal $\mathrm{Ca}^{2+}$ conditions, lowering extracellular $\mathrm{Na}^{+}$or inhibiting PKC activity reduces preNMDAR-mediated enhancement of spontaneous transmitter release. These results provide new insights into the mechanisms by which preNMDARs function.

\section{Materials and Methods}

Subjects. C57BL/6 mice were purchased from Charles River Laboratories and then bred and maintained at the University of North Carolina. Experiments were conducted between postnatal day 13 (P13) and P18 in mice of either sex. Mice were kept in a $12 \mathrm{~h}$ light/dark cycle and were provided food and water ad libitum. All experiments were conducted under the animal care guidelines for the University of North Carolina at Chapel Hill.

Cortical slice preparation. Mice were decapitated following anesthetization with pentobarbital $\mathrm{Na}^{+}(40 \mathrm{mg} / \mathrm{kg}$, i.p.). Brains were removed and placed in ice-cold dissection buffer bubbled with $95 \% \mathrm{O}_{2}$ and $5 \%$ $\mathrm{CO}_{2}$. Dissection buffered consisted of the following (in $\mathrm{mM}$ ): $87 \mathrm{NaCl}, 2.5$ $\mathrm{KCl}, 1.25 \mathrm{NaH}_{2} \mathrm{PO}_{4}, 25 \mathrm{NaHCO}_{3}, 75$ sucrose, 10 dextrose, 1.3 ascorbic acid, $7 \mathrm{MgCl}_{2}$, and $0.5 \mathrm{CaCl}_{2}$. Next, $300 \mu \mathrm{M}$ coronal slices of the visual cortex were cut using a vibrating microtome (VT1200S; Leica). Slices were placed for $20 \mathrm{~min}$ in a submersion chamber at $35^{\circ} \mathrm{C}$ containing artificial CSF (ACSF) containing the following (in mM): $124 \mathrm{NaCl}, 3 \mathrm{KCl}$, $1.25 \mathrm{Na}_{2} \mathrm{PO}_{4}, 26 \mathrm{NaHCO}_{3}, 1 \mathrm{MgCl}_{2}, 2 \mathrm{CaCl}_{2}$, and $20 \mathrm{D}$-glucose saturated with $95 \% \mathrm{O}_{2}$ and $5 \% \mathrm{CO}_{2}$ at $315 \mathrm{mOsm}$ and $\mathrm{pH}$ 7.25. After the initial 20 min recovery period, slices were allowed to recover for an additional 40 $\mathrm{min}$ at room temperature, where they were maintained until use. For electrophysiological recordings, visual cortex slices were placed in a submersion chamber warmed to $30^{\circ} \mathrm{C}$ and perfused with oxygenated ACSF. Borosilicate glass pipettes had an open tip resistance between 3 and $6 \mathrm{M} \Omega$ when filled with an internal solution containing the following (in $\mathrm{mM}$ ): $20 \mathrm{KCl}, 100$ (K)gluconate, 10 HEPES, 4 (Mg)ATP, $0.3(\mathrm{Na}) \mathrm{GTP}, 10(\mathrm{Na})$ phosphocreatine, and $1 \mathrm{MK}-801$ with $\mathrm{pH}$ adjusted to 7.25 and osmolarity adjusted to $300 \mathrm{mOsm}$ with sucrose. All recordings were performed in whole-cell configurations using a patch-clamp amplifier (Multiclamp 700A/B; Molecular Devices) and were acquired and analyzed using pClamp 9.2 or 10.2 software (Molecular Devices).

Current-clamp recordings. Action potentials were evoked either by external stimulation or by direct current injection into the postsynaptic cell. For extracellular-evoked experiments, layer (L) 2/3 pyramidal cells were recorded while L4 axons were stimulated every $30 \mathrm{~s}$ with a twoconductor cluster electrode (FHC). Current was injected to maintain a $-70 \mathrm{mV}$ resting potential if necessary. Action potentials were evoked for $5 \mathrm{~min}$ before a $10 \mathrm{~min}$ TTX (200 nM) application. To examine the effect of TTX on postsynaptic spike firing, current ( $300 \mathrm{pA}, 400 \mathrm{~ms}$ ) was injected before and after a $10 \mathrm{~min}$ TTX application.

Voltage-clamp recordings. Miniature EPSCs (mEPSCs) were recorded in the presence of the $\mathrm{GABA}_{\mathrm{A}}$ receptor antagonist picrotoxin $(50 \mu \mathrm{M})$ and the voltage-gated $\mathrm{Na}^{+}$channel blocker TTX (200 nM). Neurons were recorded while holding the postsynaptic neuron at $-80 \mathrm{mV}$; only cells with $R_{\text {series }}<30 \mathrm{M} \Omega$ and having $<20 \%$ change in $R_{\text {input }}, R_{\text {series}}$, and $I_{\text {holding }}$ were included in analysis. The combination of strong hyperpolarization and inclusion of MK-801 in the postsynaptic pipette nearly abolishes postsynaptic NMDAR activity (Corlew et al., 2007). To measure the effects of preNMDARs on synaptic function, we measured mEPSC amplitude and frequency before and after bath application of 50 $\mu \mathrm{M}$ D-APV (Fig. 1A). All statistical comparisons were made between segments of the baseline period (last 5-10 min) and the APV application period (last 5-10 min of application). Greater than 50 mEPSCs were analyzed for each comparison period in a single experiment (Turrigiano et al., 1998). Interleaved control experiments were performed for the same duration but without APV application to verify that the pharmacological agents did not affect the stability of the electrophysiological recordings (data not shown for most experiments). mEPSCs were de- tected using an automatic template detection program and verified manually (pCLAMP; Molecular Devices; Clements and Bekkers, 1997).

Pharmacological agents. D-APV, TTX, and okadaic acid were purchased from Ascent Scientific. Picrotoxin, thapsigargin, dantrolene, and cantharadin were purchased from Sigma-Aldrich. 1-(5-Isoquinolinesulfonyl)-2methylpiperazine (H7), KT5720, and GF 109203X (GFX) were purchased from Tocris Bioscience. Cyclopiazonic acid (CPA) and EGTA were purchased from EMD and Fisher Scientific, respectively.

Statistics. Data are reported as mean \pm SEM unless noted otherwise, and statistical significance was assessed using two-tailed paired or unpaired Student's $t$ tests with significance placed at $p<0.05$. For comparison of multiple groups, a one-way ANOVA was used; a Tukey-Kramer multiple-comparisons test was used for the post hoc analyses; statistical significance was defined as $p<0.05$.

\section{Results}

\section{PreNMDARs can enhance neurotransmitter release with} minimal $\mathrm{Ca}^{2+}$ requirements

Recent studies demonstrated that NMDA application can evoke axonal $\mathrm{Ca}^{2+}$ responses (Lin et al., 2010; McGuinness et al., 2010; Buchanan et al., 2012), consistent with findings that preNMDARs can promote neurotransmitter release via $\mathrm{Ca}^{2+}$. dependent mechanisms (Berretta and Jones, 1996; Cochilla and Alford, 1999; Woodhall et al., 2001; Mameli et al., 2005). Therefore, we decided to determine the signaling cascades downstream of preNMDAR activation by first clarifying the requirements for $\mathrm{Ca}^{2+}$. To determine the mechanisms of preNMDAR-mediated transmitter release, we examined the effects of NMDAR blockade on spontaneous release in the presence of TTX (200 nM). In 9 of 9 experiments, a 5 min application of this TTX concentration effectively blocked spike formation in L2/3 neurons in response to direct current injection or L4 extracellular stimulation (Fig. 1A). In addition to performing experiments in the presence of TTX, in subsequent experiments, we first blocked postsynaptic NMDARs by including the NMDAR antagonist MK-801 in the recording pipette and by strongly hyperpolarizing the postsynaptic neuron (Corlew et al., 2007). We then determined the role of preNMDARs in spontaneous transmitter release by examining how bath application of the competitive NMDAR antagonist D-APV $\left(\begin{array}{ll}50 & \mu \mathrm{M}\end{array}\right)$ altered postsynaptic AMPAR-mediated mEPSCs. As demonstrated previously under these control conditions (Corlew et al., 2007; Brasier and Feldman, 2008; Corlew et al., 2008; Larsen et al., 2011), bath application of APV reduced mEPSC frequency but not amplitude (Fig. $1 B$ ), indicating that preNMDARs tonically facilitate glutamate release. To determine the extent to which preNMDARs require $\mathrm{Ca}^{2+}$ to promote neurotransmitter release, we examined the effects of APV on spontaneous transmitter release in neurons recorded in ACSF lacking external $\mathrm{Ca}^{2+}$ and with EGTA ( $3 \mathrm{~mm}$ ) to further buffer residual $\mathrm{Ca}^{2+}$. These low $\mathrm{Ca}^{2+}$ conditions profoundly reduced mEPSC frequency compared with controls with normal ACSF $(p<0.05$; note different axes and average baseline values in Fig. $1 B_{3}$ and Fig. $1 C_{2}$ ). However, even in the nominally zero $\mathrm{Ca}^{2+}$ ACSF, APV application reduced mEPSC frequency ( $p<0.05)$, but not amplitude, compared with baseline (Fig. $1 C$ ). mEPSC frequency returned to baseline levels after APV was removed, indicating that this decrease was specific to APV application and was not a general rundown of cellular responses (Fig. $1 C_{2}$ ). Moreover, the normalized reduction in mEPSC frequency by APV in nominally zero $\mathrm{Ca}^{2+}$ ACSF was not statistically different $(p=0.82)$ than the normalized reduction in mEPSC frequency by APV in normal $\mathrm{Ca}^{2+} \operatorname{ACSF}$ (Fig. $1 C_{3}$ ). These data suggest that preNMDARs are able to promote spontaneous neurotransmitter release with minimal $\mathrm{Ca}^{2+}$ entry from extracellular sources. 


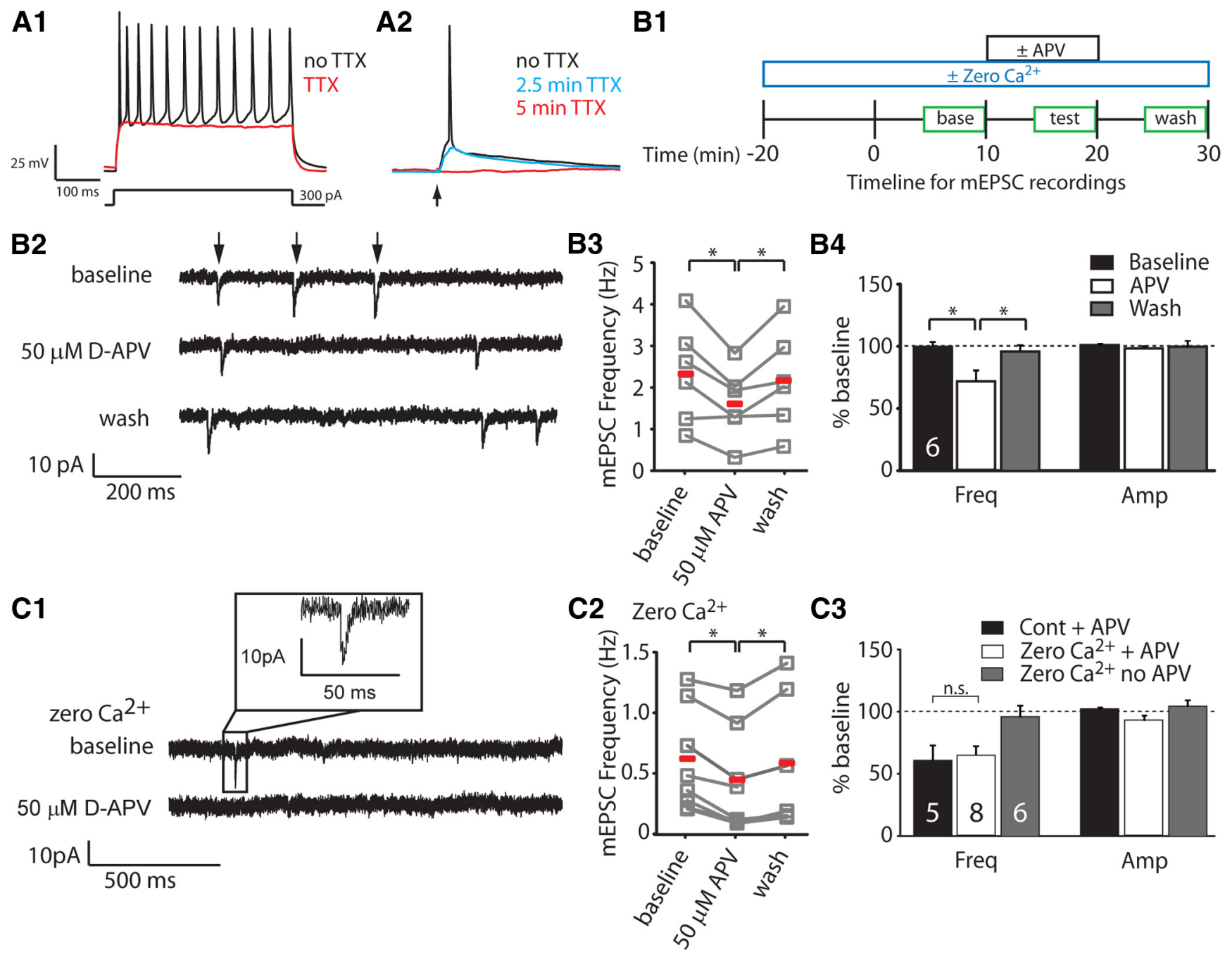

Figure 1. PreNMDARs can tonically promote neurotransmitter release with minimal $\mathrm{Ca}^{2+}$ requirements. $A_{1}$, Example trace of the response of a layer $(\mathrm{L}) 2 / 3$ pyramidal neuron to a $300 \mathrm{pA}$ current pulse. After TTX ( $200 \mathrm{~nm}$ ) was washed onto the slice for $5 \mathrm{~min}$, no action potentials were observed. $A_{2}$, Example trace measuring the response in a L2/3 pyramidal neuron to extracellular stimulation of L4. Within 5 min of TTX application, a stimulation that previously could elicit a postsynaptic spike, failed to elicit a detectable EPSP. $\boldsymbol{B}_{1}$, Schematic of the experimental protocol used to delineate the signaling pathways downstream of preNMDAR activation (see Materials and Methods and Results sections for details). $\boldsymbol{B}_{2}$, Example whole-cell recording depicting $\mathrm{mEPSCS}$ (arrows) from a L2/3 pyramidal cell in a visual cortex slice from a P15 mouse. $\boldsymbol{B}_{3}$, Scatterplot of mEPSC frequency from individual recordings in normal ACSF (baseline) demonstrating that D-APV ( $50 \mu \mathrm{M}$ ) antagonism of preNMDARs reversibly reduces mEPSC frequency in L2/3 pyramidal neurons. Group means (depicted by red bar) and SDs are as follows: baseline, 2.31 $\pm 1.2 ; A P V, 1.59 \pm 0.86 ;$ and wash, $2.14 \pm$ 1.19. $\boldsymbol{B}_{4}$, Bar chart depicting the effects of APV application on the normalized mEPSC frequency and amplitude. $\boldsymbol{C}_{1}$, Example whole-cell recording from an L2/3 pyramidal cell recorded in ACSF with nominally zero $\mathrm{Ca}^{2+} . \mathrm{C}_{2}, \mathrm{APV}$ reversibly decreases mEPSC frequency in neurons recorded in nominally zero $\mathrm{Ca}^{2+}$ [paired $t$ test; $t(8)=6.73, p<0.001$ ]. Group means (depicted by red bar) and SD are as follows: baseline, $0.63 \pm 0.43 ; \mathrm{APV}, 0.47 \pm 0.42$; and wash, $0.59 \pm 0.55$. $\mathrm{C}_{3}$, Bar graph displaying the normalized and averaged effect of APV treatment on the normalized $\mathrm{mEPSC}$ frequency and amplitude in experiments performed in control conditions with normal $\mathrm{Ca}^{2+}$ versus zero $\mathrm{Ca}^{2+}$ conditions. No statistical differences in APV effects were observed (unpaired $t$ tests; frequency: $t_{(12)}=0.62, p=0.82$; amplitude: $\left.t_{(12)}=1.57, p=0.14\right)$. In control experiments, no changes in mEPSC frequency or amplitude were observed in neurons recorded in zero $\mathrm{Ca}^{2+}$ over the same time course but in the absence of APV treatment (paired $t$ tests; frequency: $t_{(4)}=0.37, p=0.73$; amplitude: $t_{(4)}=1.66, p=0.17$ )]. Asterisk denotes significant differences from baseline. Error bars represent SEM.

PreNMDAR-mediated enhancement of spontaneous transmitter release does not require $\mathrm{Ca}^{2+}$ release from intracellular stores

Recent work has suggested that preNMDARs function through $\mathrm{Ca}^{2+}$-induced $\mathrm{Ca}^{2+}$ release (Rossi et al., 2012). Therefore, we next investigated whether intracellular $\mathrm{Ca}^{2+}$ stores were required for preNMDAR-mediated release of glutamate (Fig. 2) using pharmacological agents that disrupt release of $\mathrm{Ca}^{2+}$ from intracellular stores and that have been shown previously to affect spontaneous release (Simkus and Stricker, 2002; Collin et al., 2005). For all experiments, we first determined whether the pharmacological agent being used affected spontaneous release. Some drugs affected the baseline frequency of mEPSCs, however, we were still able to determine whether APV could modulate the drug-modified baseline. To determine the consequences of the SERCA sarco/endoplasmic reticulum $\mathrm{Ca}^{2+}$-ATPase pump antagonist, cyclopiazonic acid, (CPA; $30 \mu \mathrm{M})$, we first bathed visual cortex slices in CPA for at least $1 \mathrm{~h}$ (thereby depleting and inhibiting release of $\mathrm{Ca}^{2+}$ from these intracellular stores) (Simkus and Stricker, 2002). Despite blocking release from SERCA-sensitive intracellular stores, we still found that APV application significantly reduced mEPSC frequency $(p<0.05)$ without modifying amplitude $(p=0.12$; Fig. $2 B)$. Further, the normalized reduction in $\mathrm{mEPSC}$ frequency was not significantly different from slices incubated in normal ACSF ( $p=0.45)$. To confirm these results, we next investigated the influence of another SERCA inhibitor, thapsigargin ( $4 \mu \mathrm{M})$, compared with control conditions (Fig. 2C). As with CPA, visual cortex slices were exposed to thapsigargin for 
A

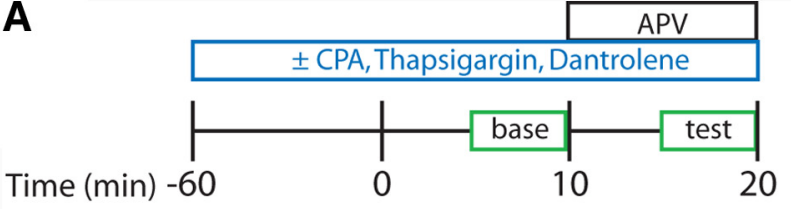

B

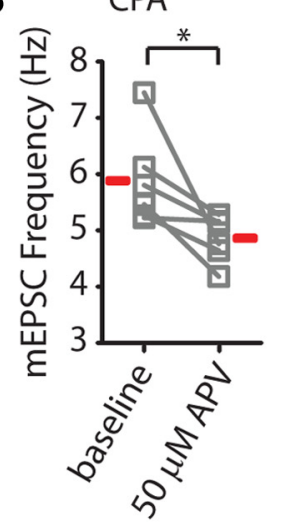

C Thapsigargin
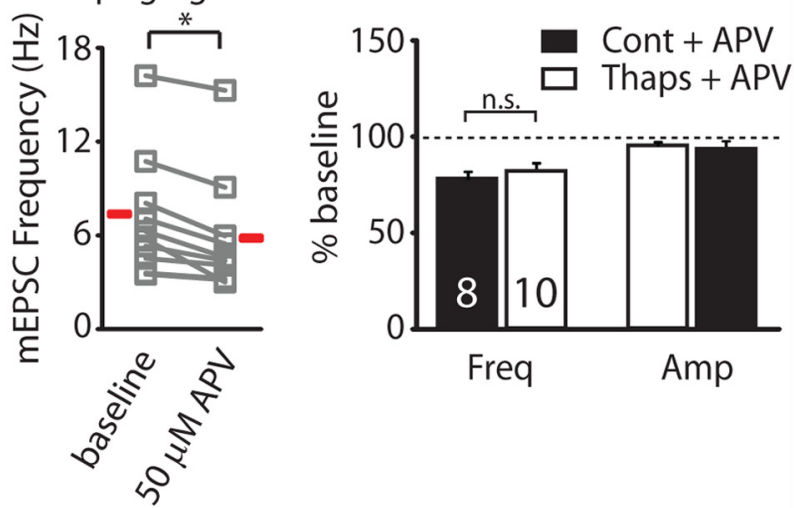

D Dantrolene
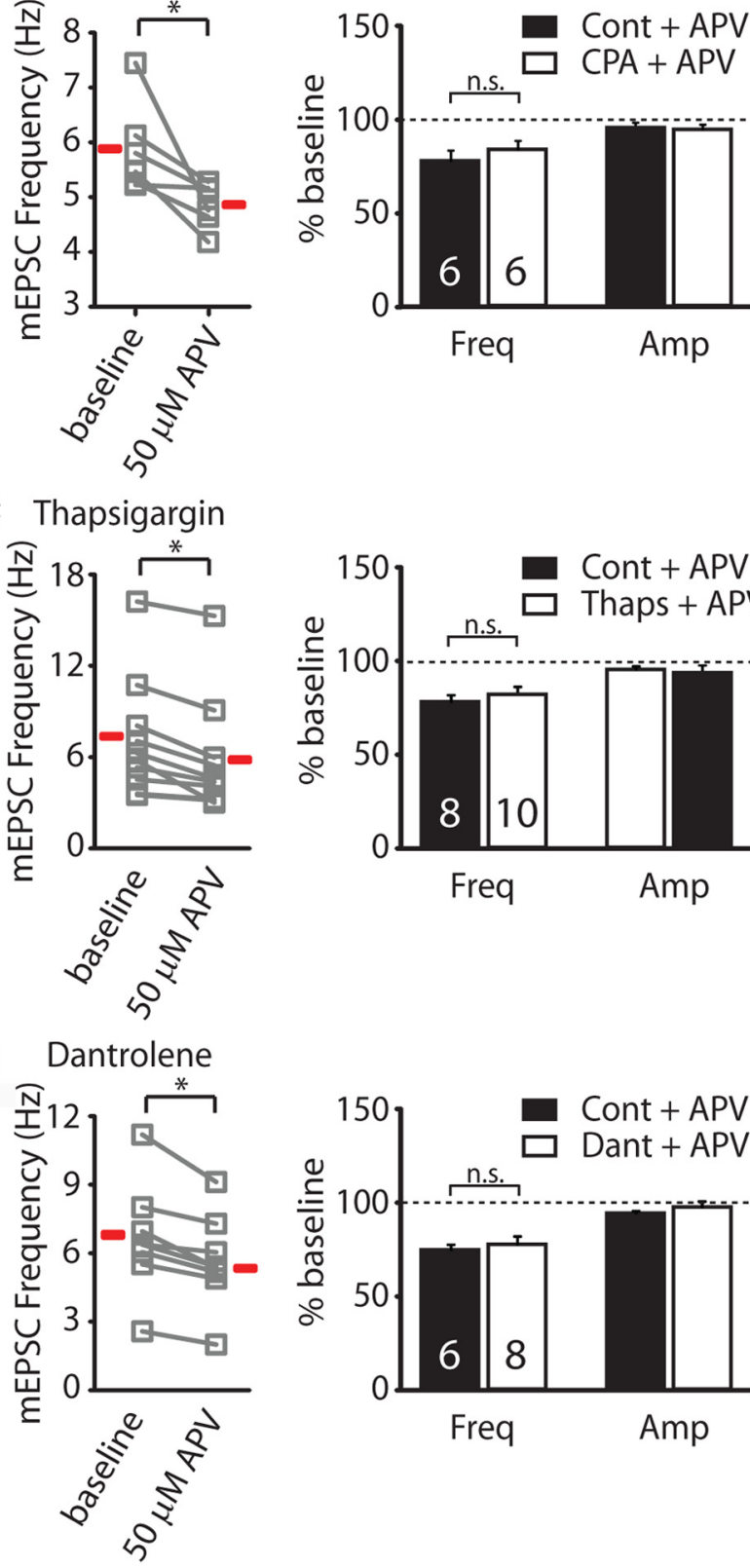

Freq

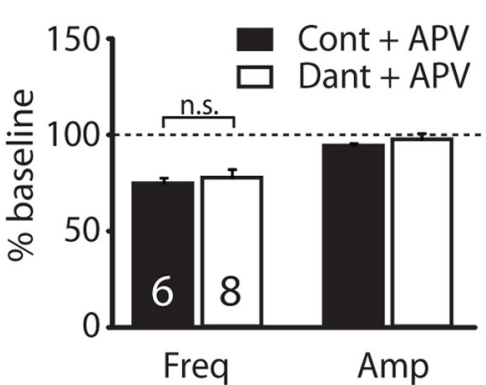

Figure 2. Calcium release from intracellular stores is not required to promote tonic preNMDAR-mediated enhancement of neurotransmitter release. $A$, Schematic of the experimental protocol. $\boldsymbol{B}-\boldsymbol{D}$, Scatterplots (left) indicate a significant reduction in mEPSC frequency for experiments performed in the presence of the SERCA inhibitors (CPA and thapsigargin) or a ryanodine antagonist (dantrolene). Group means (depicted by red bar) and SDs are as follows: CPA baseline, $5.88 \pm 0.84$; (PA APV , $4.8 \pm 0.42$; thapsigargin baseline, $7.15 \pm 3.91$; thapsigargin APV, $5.8 \pm 3.82$; dantrolene baseline, $6.52 \pm 2.32$; and dantrolene APV, $5.29 \pm 2.20$. Paired $t$ tests for all groups demonstrated that APV effectively reduced mEPSC frequency (CPA: $t_{(5)}=2.75, p<0.05$; thapsigargin: $t_{(9)}=5.01, p<0.001$; dantrolene: $t_{(7)}=4.84, p<0.01$ ). Bar graphs (right) display the normalized and averaged changes in mEPSC frequency and amplitude by APV treatment in neurons recorded in the presence of CPA, thapsigargin, dantrolene, or their interleaved controls (Cont). CPA, thapsigargin, and dantrolene treatments did not significantly affect the APV-induced reduction in mEPSC frequency compared with control at least $1 \mathrm{~h}$ before recording. In the presence of thapsigargin, APV application reduced mEPSC frequency $(p<0.05)$ without affecting amplitude $(p=0.27)$. Further, the effects of APV on mEPSC frequency under control and thapsigargin-treated slices were statistically indistinguishable $(p=0.15)$. These data suggest that preNMDARs do not require activation of SERCA-mediated $\mathrm{Ca}^{2+}$ stores to promote spontaneous transmitter release.

Finally, to test for a requirement of $\mathrm{Ca}^{2+}$ release from ryanodine-sensitive stores, we incubated visual cortex slices in the ryanodine antagonist dantrolene $(10 \mu \mathrm{M})$ for at least $1 \mathrm{~h}$ before recordings (Fig. 2D). Under these conditions, APV application still reduced mEPSC frequency $(p<0.05)$ without affecting mEPSC amplitude $(p=0.78)$. Further, dantrolene-treated and control slices responded similarly to APV treatment $(p=$ 0.43 ). These data indicate that preNMDARs can promote spontaneous transmitter release in a manner that can be independent of $\mathrm{Ca}^{2+}$ release from intracellular stores.

\section{PreNMDARs require $\mathrm{Na}^{+}$-dependent depolarization to} enhance tonic transmitter release

We were surprised that preNMDARs could continue to promote presynaptic neurotransmitter release in nominally zero $\mathrm{Ca}^{2+}$ conditions. We therefore sought to determine additional mechanisms that could contribute to preNMDAR-mediated transmitter release. Because preNMDARs can spontaneously promote neurotransmitter release in the absence of action potentials and spontaneous preNMDAR activity in the visual cortex requires GluN3A-containing NMDARs (Larsen et al., 2011), which are known to have reduced $\mathrm{Ca}^{2+}$ permeability (Das et al., 1998; Pérez-Otaño et al., 2001; Matsuda et al., 2002; Sasaki et al., 2002; Tong et al., 2008), we hypothesized that $\mathrm{Na}^{+}$-dependent depolarization may serve as an important contributor to preNMDARmediated release. Depolarization can influence presynaptic release directly by influencing voltage-gated $\mathrm{Ca}^{2+}$ channels or indirectly through the activation of intracellular signaling cascades (Leenders and Sheng, 2005). To determine the influence of depolarization, we replaced either 50\% (final concentration of 62 $\mathrm{mm}$ ) or $75 \%$ (final concentration of $31 \mathrm{~mm}$ ) of the extracellular $\mathrm{NaCl}$ with the impermeable monovalent cation $\mathrm{N}$-methyl-Dglucamine (Fig. 3). We could not completely remove $\mathrm{Na}^{+}$from the extracellular solution because $\mathrm{Na}^{+}$flow through AMPA receptors is required to measure our primary readout, AMPARmediated currents. As expected, lowering $\mathrm{NaCl}$ to $31 \mathrm{~mm}$ significantly reduced mEPSC frequency and amplitude in baseline conditions $(p<0.05)$ through a large reduction in the driving force. This large reduction $(31 \mathrm{~mm})$ in extracellular sodium was sufficient to block the reduction in mEPSC frequency by APV $(p=0.93$, paired $t$ test; Fig. $3 B)$. However, reducing extracellular $\mathrm{NaCl}$ to $62 \mathrm{~mm}$ was not sufficient to block the APV-mediated reduction in mEPSC frequency ( $p<0.05$; paired $t$ test). In addition, an ANOVA comparing the APV-induced change in normalized mEPSC frequency in the low $31 \mathrm{~mm} \mathrm{Na}^{+}$group, the $62 \mathrm{~mm}$ $\mathrm{Na}^{+}$group, and the $124 \mathrm{mM} \mathrm{Na}^{+}$group (controls) yielded a significant main effect $(p<0.05)$. Post hoc tests to probe this significant difference indicated that the $31 \mathrm{mM} \mathrm{Na}^{+}$group

$\leftarrow$

experiments performed in normal ACSF (CPA: $t_{(10)}=0.78, p=0.45$; thapsigargin: $t_{(16)}=1.41$ $p=0.15$; dantrolene: $\left.t_{(12)}=0.88, p=0.43\right)$, nor did these treatments affect the lack of APV influence on mEPSC amplitude (CPA: $t_{(10)}=0.20, p=0.85$; thapsigargin: $t_{(16)}=0.50, p=$ 0.20 ; dantrolene: $\left.t_{(12)}=0.93, p=0.62\right)$. Asterisk denotes significant differences from baseline. Error bars represent SEM. 


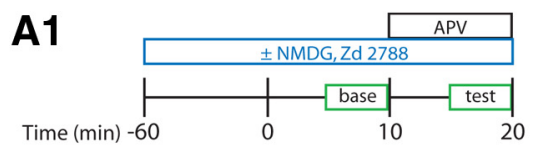

A2
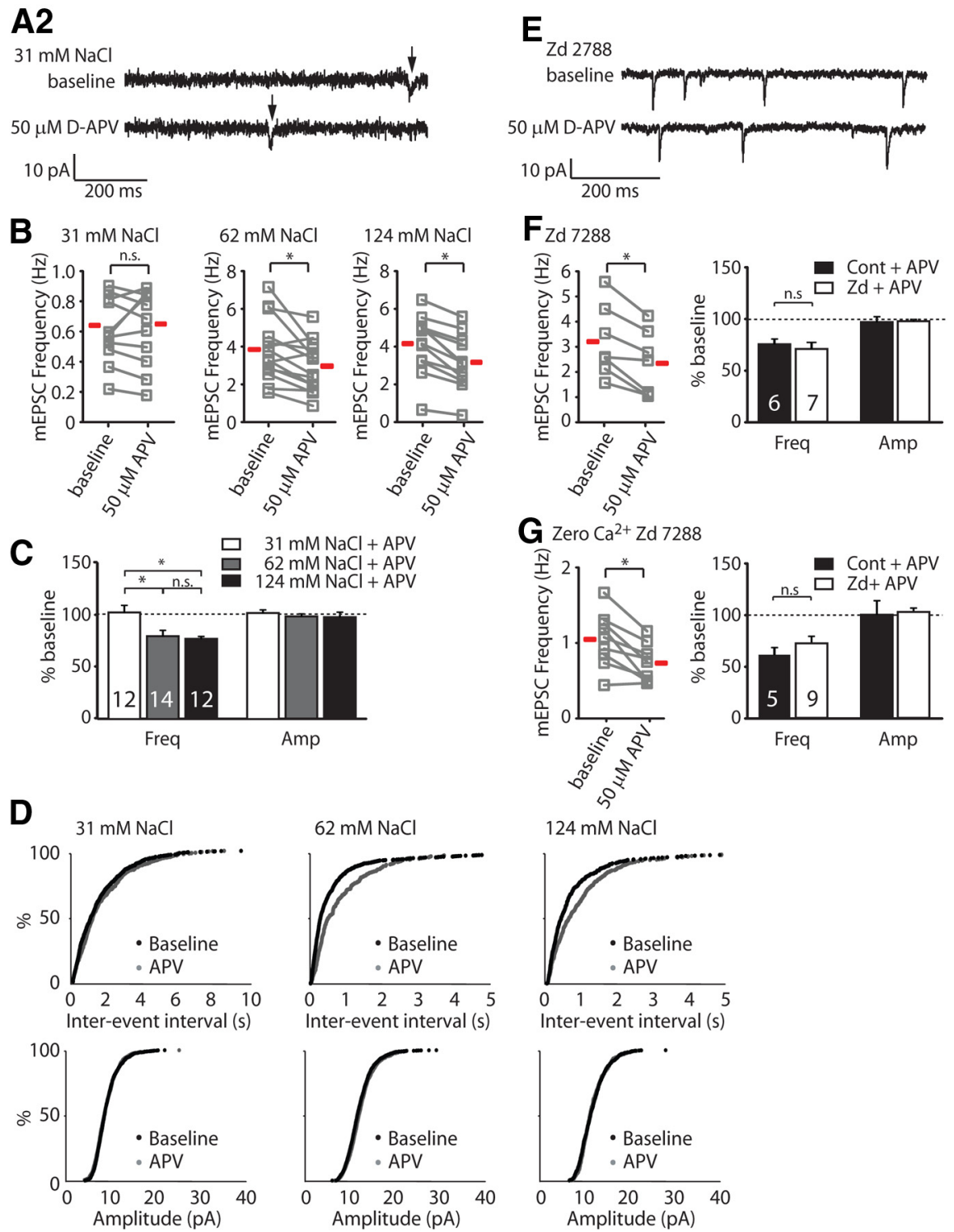

G Zero $\mathrm{Ca}^{2+} \mathrm{Zd} 7288$
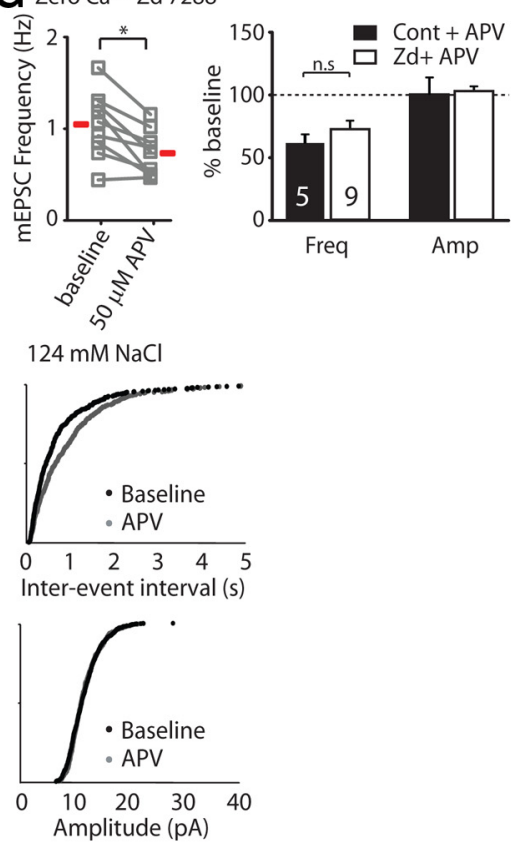

Figure 3. Partial replacement of $\mathrm{Na}^{+}$with $\mathrm{N}$-methyl-D-glucamine blocks the tonic activity of preNMDARs. $A_{1}$, Schematic depicting the experimental protocol used to test the contributions of $\mathrm{Na}^{+}$for preNMDAR function. $A_{2}$, Representative voltageclamp recordings from an experiment performed in low $\mathrm{Na}^{+}(31 \mathrm{mM})$. $\boldsymbol{B}$, Scatterplots indicating $\mathrm{mEPSC}$ frequency for experiments performed in 31 and $62 \mathrm{~mm} \mathrm{Na}{ }^{+}$during the baseline period and during APV application. APV application failed to consistently reduce $\mathrm{mEPSC}$ frequency in neurons recorded in in $31 \mathrm{~mm}$ extracellular $\mathrm{Na}^{+}\left(t_{(11)}=0.81, p=0.2\right)$, but did reduce mEPSC frequency in $62 \mathrm{~mm} \mathrm{Na}^{+}\left(t_{(13)}=2.03, p<0.01\right)$. Group means (depicted by red bar) and SDs are as follows: $31 \mathrm{~mm}$ baseline, $0.64 \pm 0.24 ; 31 \mathrm{~mm} \mathrm{APV}, 0.64 \pm 0.26 ; 62 \mathrm{~mm}$ baseline, $3.92 \pm 1.67 ; 62 \mathrm{~mm} \mathrm{APV}, 3.30 \pm 1.45 ; 124 \mathrm{~mm}$ baseline, $4.01 \pm 1.50 ;$ and $124 \mathrm{~mm} \mathrm{APV}, 3.04 \pm 1.38$. C, Bar graph displaying the normalized and averaged mEPSC frequency and amplitude in neurons recorded in $31 \mathrm{~mm}$ extracellular $\mathrm{NaCl}, 62 \mathrm{~mm}$ extracellular $\mathrm{NaCl}$, and in control $124 \mathrm{~mm}$ extracellular $\mathrm{NaCl}$. The $62 \mathrm{~mm}$ and the $124 \mathrm{~mm}$ $\mathrm{NaCl}$ groups were significantly more sensitive to APV wash compared with the $31 \mathrm{~mm}$ group as indicated by an ANOVA $\left(F_{(2,35)}=\right.$ $6.78, p<0.004$ ) and subsequent posthoc tests $(p<0.05)$. No significant differences in mESPC amplitude were observed (ANOVA $\left.F_{(2,35)}=0.51, p=0.60\right)$. Asterisks denote significant differences. $\boldsymbol{D}$, Average cumulative probability distributions of $\mathrm{mEPSC}$ frequency and amplitude under baseline conditions or during APV application. APV application shortened interevent intervals in the presence of 62 and $124 \mathrm{~mm} \mathrm{NaCl}$, but not $31 \mathrm{~mm} \mathrm{NaCl}$, and had no effect on amplitude, regardless of $\mathrm{NaCl}$ concentration. For cumulative probability plots, the same number of events were analyzed for each neuron within a condition so that interneuron differences in frequency would not skew the analysis. $\boldsymbol{E}$, Representative voltage-clamp recordings from an experiment performed in Zd 7288. $\boldsymbol{F}-\mathbf{G}$, Scatterplot (left) indicates a significant reduction in $\mathrm{mEPSC}$ frequency for experiments performed with or without external $\mathrm{Ca}^{2+}$ in the presence of the $Z \mathrm{~d} 7288$, an HCN inhibitor. Paired $t$ tests demonstrate that APV reduced mEPSC frequency in

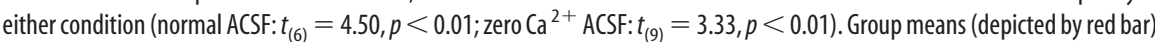
and SDs are as follows: Zd 7288 baseline, $3.20 \pm 1.40 ; Z d ~ 7288 \mathrm{APV}, 2.35 \pm 1.27$; zero $\mathrm{Ca}^{2+} \mathrm{Zd} 7288$ baseline, $1.03 \pm 0.35$; and zero $\mathrm{Ca}^{2+} \mathrm{Zd} 7288 \mathrm{APV}, 0.72 \pm 0.24$. Bar graphs (right) display the normalized and averaged changes in $\mathrm{mEPSC}$ frequency and showed less APV-induced modification of normalized mEPSC frequency compared with either the $62 \mathrm{mM} \mathrm{Na}^{+}$group or the $124 \mathrm{mM} \mathrm{Na}^{+}$group (control). Normalized mEPSC amplitude was not modified by APV application, because ANOVA failed to detect a significant difference between the various $\mathrm{Na}^{+}$ treatments $(p=0.60)$.

Presynaptic HCN channels have been shown to significantly affect presynaptic release at excitatory synapses (Huang et al., 2011). Reduction of the $\mathrm{Na}^{+}$driving force could also block modulation of neurotransmitter release by $\mathrm{HCN}$ channels and potentially confound the interpretation of our APV results. To exclude the possibility that HCN channels contribute to preNMDAR function, we sought to determine whether APV could modify presynaptic release in the presence of the $\mathrm{HCN}$ channel inhibitor $\mathrm{Zd} \mathrm{7288.} \mathrm{In} \mathrm{the}$ presence (Fig. $3 F$ ) or absence (Fig. $3 G$ ) of extracellular $\mathrm{Ca}^{2+}, \mathrm{Zd} 7288$ failed to block the reduction in mEPSC frequency compared with control solutions $(p<0.05)$, suggesting that HCN channels do not contribute to mEPSC frequency in a preNMDAR-dependent manner. These data suggest that $\mathrm{Na}^{+}$-dependent processes are important for preNMDARmediated transmitter release, but only modest extracellular $\mathrm{Na}^{+}$levels are needed. However, these data do not determine whether $\mathrm{Na}^{+}$flow depolarizes the presynaptic terminal directly, thus affecting transmitter release, or if $\mathrm{Na}^{+}$-induced depolarization begins a signaling cascade that is critical toward enhancing presynaptic function.

\section{Influence of kinase and phosphatase pathways on preNMDAR-mediated transmitter release}

Having established a role for $\mathrm{Na}^{+}$influx in preNMDAR function, which likely works in addition to the established role for $\mathrm{Ca}^{2+}$-mediated effects (Lin et al., 2010; McGuinness et al., 2010), we then began to investigate downstream signaling cascades. Because the phosphoryla-

\section{$\leftarrow$}

amplitude by APV treatment in neurons recorded in the presence of Zd 7288 or the interleaved controls. Zd 7288 did not significantly affect the APV-induced reduction in mEPSC frequency compared with control experiments performed in normal ACSF $\left(t_{(11)}=0.56, p=0.23\right)$ or zero $\mathrm{Ca}^{2+}$ ACSF $\left(t_{(13)}=1.37, p=0.19\right)$, nor did these treatments affect the lack of APV influence on mEPSC amplitude (normal ACSF: $t_{(11)}=1.35, p=0.21$; zero $\mathrm{Ca}^{2+}$ ACSF: $t_{(13)}=0.15, p=$ 0.88 ). Asterisk denote significant differences from baseline. Error bars represent SEM. 


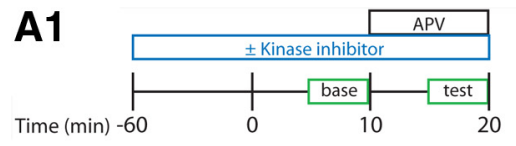

A2
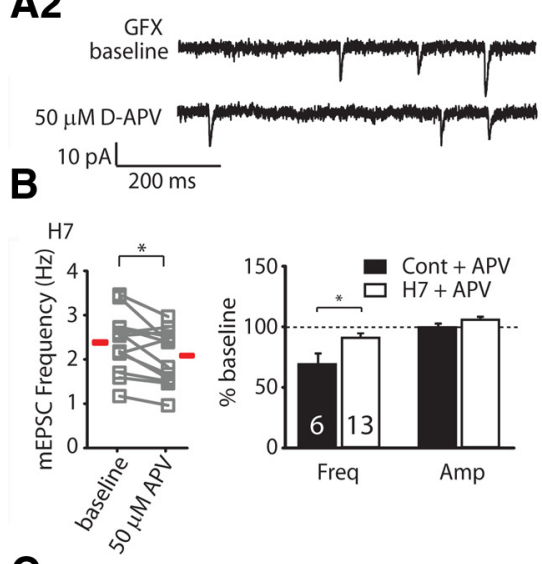

C $_{\mathrm{Gfx}}$

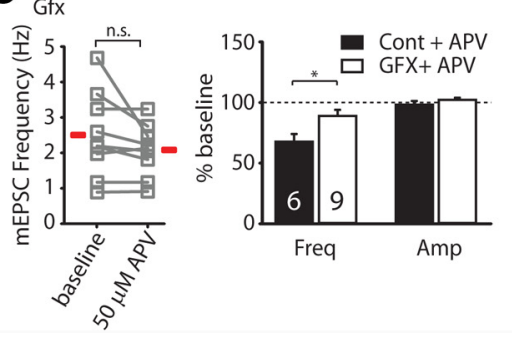

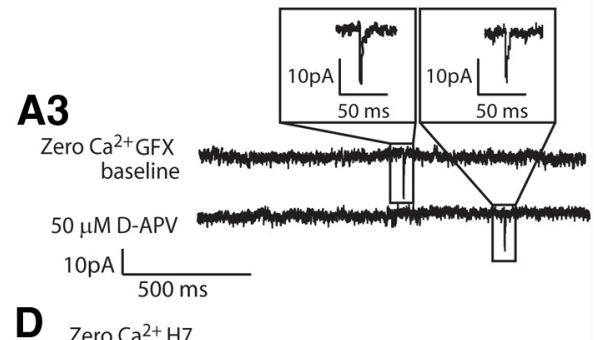

D Zero $\mathrm{Ca}^{2+} \mathrm{H7}$

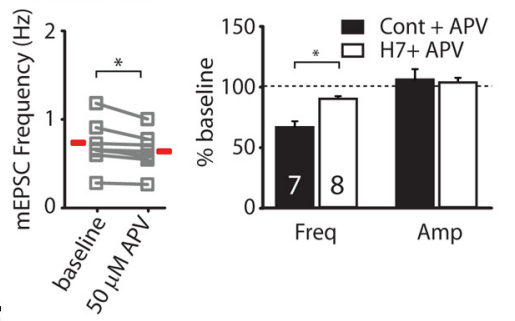

E

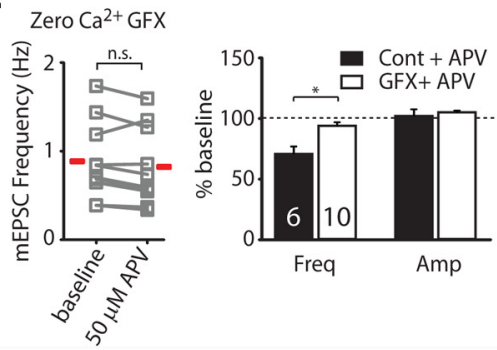

Figure 4. Role of kinase activity in tonic preNMDAR activity. $\boldsymbol{A}_{\mathbf{1}}$, Schematic showing the experimental protocol used to test the requirement of kinase activity for preNMDAR function. All inhibitors were bath applied for at least $1 \mathrm{~h}$ before experimentation. $A_{2-3}$, Representative voltage-clamp recordings from an experiment performed in the presence of the PKC inhibitor GFX in normal or zero $\mathrm{Ca}^{2+}$ ACSF. $\boldsymbol{B}, \boldsymbol{C}$, Scatterplots (left) indicate significant reductions after APV application for experiments performed in the broad kinase inhibitor H7 (paired $t$ test: $t_{(12)}=2.91, p<0.01$ ) and the PKC inhibitor GFX (paired $t$ test: $t_{(8)}=1.72, p<0.05$ ). Group means (depicted by red bar) and SDs are as follows: H7 baseline, $2.45 \pm 0.67 ; \mathrm{H7}$ APV, $2.15 \pm 0.62 ;$ GFX baseline, $2.53 \pm$ 1.21; and GFX APV, $2.10 \pm 0.74$. Bar graphs (right) display the normalized mEPSC frequency for groups incubated and tested in $\mathrm{H7}$ and GFX that were significantly different from the normalized frequency of groups incubated and tested in normal ACSF (unpaired $t$ tests: H7: $t_{(17)}=2.62, p<0.02 ;$ GFX: $t_{(13)}=0.45, p<0.03$ ). No statistical differences in normalized mEPSC amplitude were observed between groups tested in kinase inhibitors and normal ACSF (unpaired $t$ tests; H7: $t_{(17)}=0.87, p=0.47 ; 10 \mu \mathrm{m} \mathrm{GFX:}$ $t_{(13)}=1.07, p=0.25$ ). Asterisks denote significant differences. $\boldsymbol{D}, \boldsymbol{E}$, Scatterplots (left) indicate significant reductions after APV application for experiments performed in zero $\mathrm{Ca}^{2+}$ ACSF in the presence of $\mathrm{H7}$ (paired $t$ test: $t_{(7)}=5.63, p<0.001$ ) and GFX (paired $t$ test: $t_{(9)}=2.74, p<0.05$ ). Group means (depicted by red bar) and SDs are as follows: zero $\mathrm{Ca}^{2+} \mathrm{H7}$ baseline, $0.55 \pm$ 0.25; zero $\mathrm{Ca}^{2+}$ H7 APV, $0.48 \pm 0.21$; zero $\mathrm{Ca}^{2+}$ GFX baseline, $0.89 \pm 0.43$; and zero $\mathrm{Ca}^{2+}$ GFX APV, $0.83 \pm 0.43$. Bar graphs (right) display the normalized mEPSC frequency for groups incubated and tested in $\mathrm{H} 7 /$ zero $\mathrm{Ca}^{2+} \mathrm{ACSF}$ and GFX/zero Ca ${ }^{2+} \mathrm{ACSF}$ that were significantly different from the normalized frequency of groups incubated and tested in zero $\mathrm{Ca}^{2+}$ ACSF (unpaired $t$ tests: H7: $t_{(13)}=4.63, p<0.001 ;$ GFX: $\left.t_{(14)}=3.87, p<0.01\right)$. No statistical differences in normalized mEPSC amplitude were observed between groups tested in kinase inhibitors and zero $\mathrm{Ca}^{2+} \mathrm{ACSF}$ (unpaired $t$ tests; $\mathrm{H7}: t_{(13)}=0.55, p=0.59 ; \mathrm{GFX}: t_{(14)}=$ $0.35, p=0.73$ ). Asterisks denote significant differences. Error bars represent SEM.

tion state of presynaptic proteins has a profound influence upon presynaptic efficacy (Leenders and Sheng, 2005), we investigated whether phosphatase or kinase activation was required for preNMDAR-dependent transmitter release.

We found no evidence that blocking phosphatase activity with cantharidin $(10 \mu \mathrm{M})$ or okadaic acid $(1 \mu \mathrm{M})$ could affect preNMDAR-mediated enhancement of transmitter release (data not shown), so we sought to determine the role of kinase activity on this phenomenon using a broad-spectrum kinase inhibitor, H7. After incubating our slices in $\mathrm{H} 7(10 \mu \mathrm{M})$ for at least $1 \mathrm{~h}$ (Fig. $4 B$ ), we observed a significant reduction in mEPSC frequency from baseline in response to APV $(p<0.05)$, with no change in mEPSC amplitude $(p=0.35)$. However, when the normalized reduction in mEPSC frequency by APV was compared between the control group and the $\mathrm{H} 7$ group, we observed a significant difference $(p<0.05)$. These findings suggest that kinase activity is at least partially required for preNMDARs to influence presynaptic release. Because $\mathrm{H} 7$ is a broad kinase inhibitor, we next sought to determine which specific kinases influenced preNMDAR activity by incubating the slices in KT5720 (1 $\mu \mathrm{M})$, a PKA inhibitor. APV significantly reduced mEPSC frequency in the presence of KT5720 (data not shown; $p<0.05)$. No changes in mEPSC amplitude were observed $(p=$ $0.54)$. When we compared the normalized reduction in mEPSC frequency with a control group given APV in normal ACSF, no significant difference was observed $(p=0.95)$, suggesting that PKA activity was not required for preNMDARs to affect presynaptic transmitter release. We next investigated the role of PKC by bathing our slices in GFX $(10 \mu \mathrm{M})$, a specific inhibitor of PKC. APV failed to reduce $\mathrm{mEPSC}$ frequency in the presence of GFX ( $p>0.05$; Fig. $4 C)$, with no change in mEPSC amplitude $(p=0.68)$. In addition, slices incubated with GFX were significantly less sensitive to changes in normalized mEPSC frequency during the APV wash compared with the ACSF controls $(p<0.05)$. No change in mEPSC amplitude was measured $(p=0.53)$. These data suggest that PKC activity is partially required for preNMDAR function. We next sought to determine whether these mechanisms contribute to preNMDAR function in the modified zero $\mathrm{Ca}^{2+}$ ACSF. In nominally zero $\mathrm{Ca}^{2+}$, H7 and GFX still blocked the effect of APV on mEPSC frequency without affecting mEPSC amplitude [(H7: normalized mEPSC frequency, $p<0.05$; normalized mEPSC amplitude, $p=0.69$ ) and (GFX: normalized mEPSC frequency, $p<0.05$; normalized mESPC amplitude, $p=0.73$ )] compared with zero $\mathrm{Ca}^{2+}$ ACSF controls (Fig. 4D,E). This suggests that key mechanisms for preNMDAR-mediated enhancement of neurotransmitter release function in the presence or absence of $\mathrm{Ca}^{2+}$.

\section{Discussion}

The goal of this study was to help to elucidate the cellular mechanisms that operate downstream of preNMDAR activation to enhance neurotransmitter release. Our evidence indicates that the preNMDAR-dependent signaling pathways responsible for enhancing presynaptic neurotransmitter release can operate in nominally zero extracellular $\mathrm{Ca}^{2+}$. Further, we also show that release of $\mathrm{Ca}^{2+}$ from intracellular stores is not required. Our data demonstrate that preNMDARs can function with minimal $\mathrm{Ca}^{2+}$ requirements and may even be able to function in a $\mathrm{Ca}^{2+}$-independent manner. There is also good evidence that preNMDARs may normally promote transmitter release through $\mathrm{Ca}^{2+}$-dependent mechanisms (Berretta and Jones, 1996; Cochilla 
and Alford, 1999; Woodhall et al., 2001; Mameli et al., 2005; McGuinness et al., 2010; Buchanan et al., 2012). These data suggest that there may be two mechanisms underlying preNMDARinfluenced vesicular release: one that requires normal levels of extracellular $\mathrm{Ca}^{2+}$ and another that can affect release in a largely $\mathrm{Ca}^{2+}$-independent manner. Although we were surprised to see that preNMDARs could continue to promote spontaneous transmitter release with minimal $\mathrm{Ca}^{2+}$ requirements, this observation is consistent with a recent finding from our laboratory indicating that preNMDARs in the visual cortex are triheteromeric NMDARs with low $\mathrm{Ca}^{2+}$ permeability (Larsen et al., 2011). Specifically, tonic preNMDAR activity appears to require GluN1, GluN2B, and GluN3A subunits (Brasier and Feldman, 2008; Larsen et al., 2011). These GluN3A-containing NMDARs have interesting properties that make them ideally suited for a role in presynaptic release. First, these NMDARs are relatively insensitive to magnesium block near resting membrane potentials, allowing them to function tonically in a non-Hebbian manner. Second, these receptors have relatively low $\mathrm{Ca}^{2+}$ permeability, consistent with our finding that extracellular $\mathrm{Ca}^{2+}$ may not be required for tonic preNMDAR enhancement of transmitter release. We predict that NMDAR blockade by APV would not affect mEPSC frequency in low $\mathrm{Ca}^{2+}$ solutions in visual cortical slices from GluN3A knock-out mice, because the APV effect on mEPSC frequency is lost in normal ACSF in these mice (Larsen et al., 2011).

Although both $\mathrm{Ca}^{2+}$-dependent and $\mathrm{Ca}^{2+}$-independent mechanisms support preNMDAR enhancement of transmitter release, there is also an important contribution of $\mathrm{Na}^{+}$influx to preNMDAR-mediated transmitter release. The most parsimonious explanation is that $\mathrm{Na}^{+}$influx provides depolarization of the presynaptic terminal, which in turn activates a voltage-sensitive signaling cascade that affects presynaptic release. However, we cannot exclude the possibility that $\mathrm{Na}^{+}$is serving as the second messenger to mediate these effects. Nor can we rule out a role of $\mathrm{Na}^{+} / \mathrm{Ca}^{2+}$ exchange and subsequent effects upon voltage-gated $\mathrm{Ca}^{2+}$ channels (Korn and Horn, 1989), or that $\mathrm{Na}^{+}$could serve directly to facilitate $\mathrm{Ca}^{2+}$ entry through preNMDARs. Further, we cannot rule out other, less parsimonious interpretations of the reduced $\mathrm{Na}^{+}$experiments. Finally, presynaptic HCN channels have been shown to modulate presynaptic release at glutamatergic synapses (Huang et al., 2011). Although these channels are active at rest and would be affected by a low $\mathrm{Na}^{+}$solution, we found no evidence for their involvement in preNMDARmediated spontaneous release.

The signaling cascades involved in preNMDAR enhancement of transmitter release are largely unknown. Our data begin to provide some insights because we demonstrate that blockade of phosphatase activity fails to prevent preNMDAR enhancement of spontaneous release. However, we did determine that kinase activity, specifically PKC activity, helps to promote preNMDAR transmitter release. It is difficult to determine whether PKC involvement is direct or indirect-is PKC activated directly by preNMDAR-mediated depolarization or by downstream signaling cascades? PKC activity can facilitate transmitter release in both a $\mathrm{Ca}^{2+}$-dependent and a $\mathrm{Ca}^{2+}$-independent manners (Koponen et al., 1999; Saitoh et al., 2001; Scholze et al., 2002), which is consistent with our observations that the $\mathrm{Ca}^{2+}$ requirements necessary to support preNMDAR-transmitter release can be minimal.

Despite progress in determining the subunit composition, localization, and function of preNMDARs (Brasier and Feldman, 2008; Christie and Jahr, 2008; Corlew et al., 2008; Larsen et al.,
2011), there is still much to learn about how preNMDAR activity promotes tonic transmitter release. We have begun to elucidate this process by showing that tonic activation of preNMDARs enhances transmitter release through a depolarization-dependent mechanism. Although preNMDARs enhance transmitter release through $\mathrm{Ca}^{2+}$-dependent mechanisms (Berretta and Jones, 1996; Cochilla and Alford, 1999; Woodhall et al., 2001; Mameli et al., 2005; McGuinness et al., 2010; Buchanan et al., 2012), our work shows that preNMDARs can continue to enhance transmitter release with a minimal requirement for $\mathrm{Ca}^{2+}$ and that preNMDARs enhance transmitter release in part through a PKCdependent pathway. These insights suggest that preNMDARs are capable of promoting transmitter release via a noncanonical signaling pathway that is largely independent of a direct link to $\mathrm{Ca}^{2+}$-dependent release machinery, as well as through a more traditional $\mathrm{Ca}^{2+}$-dependent pathway.

\section{References}

Aoki C, Venkatesan C, Go CG, Mong JA, Dawson TM (1994) Cellular and subcellular localization of NMDA-R1 subunit immunoreactivity in the visual cortex of adult and neonatal rats. J Neurosci 14:5202-5222. Medline

Autry AE, Adachi M, Nosyreva E, Na ES, Los MF, Cheng PF, Kavalali ET, Monteggia LM (2011) NMDA receptor blockade at rest triggers rapid behavioural antidepressant responses. Nature 475:91-95. CrossRef Medline

Bender VA, Bender KJ, Brasier DJ, Feldman DE (2006) Two coincidence detectors for spike timing-dependent plasticity in somatosensory cortex. J Neurosci 26:4166-4177. CrossRef Medline

Berretta N, Jones RS (1996) Tonic facilitation of glutamate release by presynaptic $N$-methyl-D-aspartate autoreceptors in the entorhinal cortex. Neuroscience 75:339-344. CrossRef Medline

Brasier DJ, Feldman DE (2008) Synapse-specific expression of functional presynaptic NMDA receptors in rat somatosensory cortex. J Neurosci 28:2199-2211. CrossRef Medline

Buchanan KA, Blackman AV, Moreau AW, Elgar D, Costa RP, Lalanne T, Tudor Jones AA, Oyrer J, Sjöström PJ (2012) Target-specific expression of presynaptic NMDA receptors in neocortical microcircuits. Neuron 75:451-466. CrossRef Medline

Charton JP, Herkert M, Becker CM, Schröder H (1999) Cellular and subcellular localization of the 2B-subunit of the NMDA receptor in the adult rat telencephalon. Brain Res 816:609-617. CrossRef Medline

Christie JM, Jahr CE (2008) Dendritic NMDA receptors activate axonal calcium channels. Neuron 60:298-307. CrossRef Medline

Christie JM, Jahr CE (2009) Selective expression of ligand-gated ion channels in L5 pyramidal cell axons. J Neurosci 29:11441-11450. CrossRef Medline

Clements JD, Bekkers JM (1997) Detection of spontaneous synaptic events with an optimally scaled template. Biophys J 73:220-229. CrossRef Medline

Cochilla AJ, Alford S (1999) NMDA receptor-mediated control of presynaptic calcium and neurotransmitter release. J Neurosci 19:193-205. Medline

Collin T, Marty A, Llano I (2005) Presynaptic calcium stores and synaptic transmission. Curr Opin Neurobiol 15:275-281. CrossRef Medline

Corlew R, Wang Y, Ghermazien H, Erisir A, Philpot BD (2007) Developmental switch in the contribution of presynaptic and postsynaptic NMDA receptors to long-term depression. J Neurosci 27:9835-9845. CrossRef Medline

Corlew R, Brasier DJ, Feldman DE, Philpot BD (2008) Presynaptic NMDA receptors: newly appreciated roles in cortical synaptic function and plasticity. Neuroscientist 14:609-625. CrossRef Medline

Coyle JT (2006) Glutamate and schizophrenia: beyond the dopamine hypothesis. Cell Mol Neurobiol 26:365-384. CrossRef Medline

Cull-Candy S, Brickley S, Farrant M (2001) NMDA receptor subunits: diversity, development and disease. Curr Opin Neurobiol 11:327-335. CrossRef Medline

Das S, Sasaki YF, Rothe T, Premkumar LS, Takasu M, Crandall JE, Dikkes P, Conner DA, Rayudu PV, Cheung W, Chen HS, Lipton SA, Nakanishi N 
(1998) Increased NMDA current and spine density in mice lacking the NMDA receptor subunit NR3A. Nature 393:377-381. CrossRef Medline

Fan MM, Raymond LA (2007) N-methyl-D-aspartate (NMDA) receptor function and excitotoxicity in Huntington's disease. Prog Neurobiol 81: 272-293. CrossRef Medline

Filali M, Lalonde R, Rivest S (2011) Subchronic memantine administration on spatial learning, exploratory activity, and nest-building in an APP/PS1 mouse model of Alzheimer's disease. Neuropharmacology 60:930-936. CrossRef Medline

Hestrin S, Nicoll RA, Perkel DJ, Sah P (1990) Analysis of excitatory synaptic action in pyramidal cells using whole-cell recording from rat hippocampal slices. J Physiol 422:203-225. Medline

Huang Z, Lujan R, Kadurin I, Uebele VN, Renger JJ, Dolphin AC, Shah MM (2011) Presynaptic HCN1 channels regulate Cav3.2 activity and neurotransmission at select cortical synapses. Nat Neurosci 14:478-486. CrossRef Medline

Kemp JA, McKernan RM (2002) NMDA receptor pathways as drug targets. Nat Neurosci 5:1039-1042. CrossRef Medline

Koponen S, Keinänen R, Roivainen R, Hirvonen T, Narhi M, Chan PH, Koistinaho J (1999) Spreading depression induces expression of calcium-independent protein kinase $\mathrm{C}$ subspecies in ischaemia-sensitive cortical layers: regulation by $\mathrm{N}$-methyl-D-aspartate receptors and glucocorticoids. Neuroscience 93:985-993. CrossRef Medline

Korn SJ, Horn R (1989) Influence of sodium-calcium exchange on calcium current rundown and the duration of calcium-dependent chloride currents in pituitary cells, studied with whole cell and perforated patch recording. J Gen Physiol 94:789-812. CrossRef Medline

Larsen RS, Corlew RJ, Henson MA, Roberts AC, Mishina M, Watanabe M, Lipton SA, Nakanishi N, Pérez-Otaño I, Weinberg RJ, Philpot BD (2011) NR3A-containing NMDARs promote neurotransmitter release and spike timing-dependent plasticity. Nat Neurosci 14:338-344. CrossRef Medline

Lau CG, Zukin RS (2007) NMDA receptor trafficking in synaptic plasticity and neuropsychiatric disorders. Nat Rev Neurosci 8:413-426. CrossRef Medline

Leenders AG, Sheng ZH (2005) Modulation of neurotransmitter release by the second messenger-activated protein kinases: implications for presynaptic plasticity. Pharmacol Ther 105:69-84. CrossRef Medline

Lin H, Vicini S, Hsu FC, Doshi S, Takano H, Coulter DA, Lynch DR (2010) Axonal alpha7 nicotinic ACh receptors modulate presynaptic NMDA receptor expression and structural plasticity of glutamatergic presynaptic boutons. Proc Natl Acad Sci U S A 107:16661-16666. CrossRef Medline

Lipton SA (2004) Paradigm shift in NMDA receptor antagonist drug development: molecular mechanism of uncompetitive inhibition by memantine in the treatment of Alzheimer's disease and other neurologic disorders. J Alzheimers Dis 6:S61-74. Medline

Mameli M, Carta M, Partridge LD, Valenzuela CF (2005) Neurosteroidinduced plasticity of immature synapses via retrograde modulation of presynaptic NMDA receptors. J Neurosci 25:2285-2294. CrossRef Medline

Matsuda K, Kamiya Y, Matsuda S, Yuzaki M (2002) Cloning and characterization of a novel NMDA receptor subunit NR3B: a dominant subunit that reduces calcium permeability. Brain Res Mol Brain Res 100:43-52. CrossRef Medline

McGuinness L, Taylor C, Taylor RD, Yau C, Langenhan T, Hart ML, Christian H, Tynan PW, Donnelly P, Emptage NJ (2010) Presynaptic
NMDARs in the hippocampus facilitate transmitter release at theta frequency. Neuron 68:1109-1127. CrossRef Medline

Mueller HT, Meador-Woodruff JH (2004) NR3A NMDA receptor subunit mRNA expression in schizophrenia, depression and bipolar disorder. Schizophr Res 71:361-370. CrossRef Medline

Pérez-Otaño I, Ehlers MD (2004) Learning from NMDA receptor trafficking: clues to the development and maturation of glutamatergic synapses. Neurosignals 13:175-189. CrossRef Medline

Pérez-Otaño I, Schulteis CT, Contractor A, Lipton SA, Trimmer JS, Sucher NJ, Heinemann SF (2001) Assembly with the NR1 subunit is required for surface expression of NR3A-containing NMDA receptors. J Neurosci 21:1228-1237. Medline

Rice AC, DeLorenzo RJ (1998) NMDA receptor activation during status epilepticus is required for the development of epilepsy. Brain Res 782: 240-247. CrossRef Medline

Rodríguez-Moreno A, Banerjee A, Paulsen O (2010) Presynaptic NMDA Receptors and Spike Timing-Dependent Depression at Cortical Synapses. Front Synaptic Neurosci 2:18. Medline

Rossi B, Ogden D, Llano I, Tan YP, Marty A, Collin T (2012) Current and calcium responses to local activation of axonal NMDA receptors in developing cerebellar molecular layer interneurons. PLoS One 7:e39983. CrossRef Medline

Saitoh N, Hori T, Takahashi T (2001) Activation of the epsilon isoform of protein kinase $\mathrm{C}$ in the mammalian nerve terminal. Proc Natl Acad Sci U S A 98:14017-14021. CrossRef Medline

Sasaki YF, Rothe T, Premkumar LS, Das S, Cui J, Talantova MV, Wong HK, Gong X, Chan SF, Zhang D, Nakanishi N, Sucher NJ, Lipton SA (2002) Characterization and comparison of the NR3A subunit of the NMDA receptor in recombinant systems and primary cortical neurons. J Neurophysiol 87:2052-2063. Medline

Scholze T, Moskvina E, Mayer M, Just H, Kubista H, Boehm S (2002) Sympathoexcitation by bradykinin involves $\mathrm{Ca}^{2+}$-independent protein kinase C. J Neurosci 22:5823-5832. Medline

Simkus CR, Stricker C (2002) The contribution of intracellular calcium stores to mEPSCs recorded in layer II neurones of rat barrel cortex. J Physiol 545:521-535. CrossRef Medline

Sjöström PJ, Turrigiano GG, Nelson SB (2003) Neocortical LTD via coincident activation of presynaptic NMDA and cannabinoid receptors. Neuron 39:641-654. CrossRef Medline

Sze C, Bi H, Kleinschmidt-DeMasters BK, Filley CM, Martin LJ (2001) N-Methyl-D-aspartate receptor subunit proteins and their phosphorylation status are altered selectively in Alzheimer's disease. J Neurol Sci 182: 151-159. CrossRef Medline

Tong G, Takahashi H, Tu S, Shin Y, Talantova M, Zago W, Xia P, Nie Z, Goetz T, Zhang D, Lipton SA, Nakanishi N (2008) Modulation of NMDA receptor properties and synaptic transmission by the NR3A subunit in mouse hippocampal and cerebrocortical neurons. J Neurophysiol 99: 122-132. CrossRef Medline

Turrigiano GG, Leslie KR, Desai NS, Rutherford LC, Nelson SB (1998) Activity-dependent scaling of quantal amplitude in neocortical neurons. Nature 391:892-896. CrossRef Medline

Woodhall G, Evans DI, Cunningham MO, Jones RS (2001) NR2Bcontaining NMDA autoreceptors at synapses on entorhinal cortical neurons. J Neurophysiol 86:1644-1651. Medline

Yao H, Dan Y (2005) Synaptic learning rules, cortical circuits, and visual function. Neuroscientist 11:206-216. CrossRef Medline 